\title{
PENGARUH REVITALISASI PRODUK WISATA TERHADAP PREFERENSI MENGUNJUNGI PANTAI BALI LESTARI
}

\author{
Betaria Nababan ${ }^{1)^{*}}$, \& Sienny ${ }^{2)}$ \\ 1) Fakultas Ekonomi, Universitas Negeri Medan \\ 2) Fakultas Ekonomi, Universitas Negeri Medan \\ E-mail : betarianababan20@gmail.com
}

\begin{abstract}
Abstrak
Penelitian ini bertujuan untuk mengetahui Pengaruh Revitalisasi Produk Wisata terhadap Preferensi Mengunjungi. Penelitian ini dilakukan di Pantai Bali Lestari, jalan Mayjen Haji T. Rizal Nurdin Pantai Cermin kanan, Pantai Cermin Kabupaten Serdang Bedagai - Sumatera Utara 20987. Dengan populasi sebanyak 5.545 orang yang merupakan pengunjung pantai selama satu minggu terakhir pada bulan januari 2017. Dengan menggunakan Purposive Sampling di tetapkan sebanyak 98 orang sebagai sampel. Data dikumpulkan dengan menggunakan kuesioner dan diolah dengan SPSS 20.0. Teknik analisi data yang digunakan adalah regresi linear berganda dengan rumus $Y=a+b_{1} X_{1}+b_{2} X_{2}+b_{3} X_{3}+e$. Hasil penelitian menunjukkan bahwa variabel Atraksi Wisata, Amenitas, dan Aksebilitas secara simultan berpengaruh terhadap Preferensi mengunjungi.
\end{abstract}

\section{Kata kunci : Revitalisasi Produk Wisata, Preferensi Mengunjungi}

\begin{abstract}
This study aims to determine the Influence of Tourism Product Revitalization on Visiting Preference. This research was conducted at Bali Lestari beach, Jalan Mayjen Haji T. Rizal Nurdin Cermin beach right, Cermin beach Serdang Bedagai Regency - North Sumatera 20987. With a population of 5,545 people who are beach visitors during the last week in januari 2017. By using Purposive Sampling is set by 98 people as sample. Data were collected by questionnaire and processed with SPSS 20.0. Data analysis technique used is multiple linear regression with the formula $Y=a+b 1 X 1+b 2 X 2+b 3 X 3+e$. The results showed that Tourist Attraction, Amenitas, and Aksebilitas variables simultaneously affect the visiting Preference.
\end{abstract}

\section{Keywords: Tourism Product Revitalization, Visiting Preference}

\section{PENDAHULUAN}

Saat ini kegiatan pariwisata dikategorikan kedalam kelompok industri terbesar dunia dan memiliki prospek peluang besar. Berbagai negara termasuk Indonesia turut menikmati dampak dari peningkatan pariwisata dunia. Sektor pariwisata
Indonesia merupakan salah satu sektor yang menjadi tumpuan bagi pemerintah untuk meningkatkan kondisi perekonomian negara. Peranan utama sektor pariwisata dalam hal perekonomian indonesia adalah sebagai penambah devisa negara. Devisa negara dihasilkan dari 
besarnya pengeluaran wisatawan mancanegara maupun wisatawan lokal yang berkunjung ke Indonesia.

Tabel 1.1 Jumlah Kunjungan Wisman ke Sumatera Utara dan Indonesia Bulan Mei dan Juni dalam Lima Tahun Terakhir

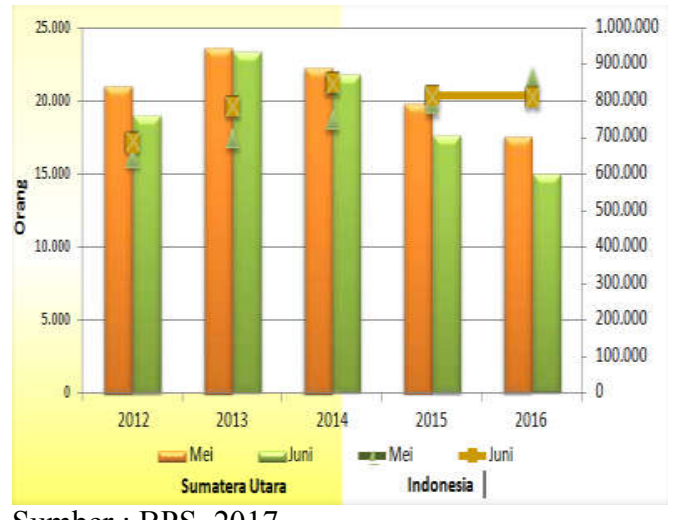

Sumber : BPS, 2017

Dengan keterangan jumlah pengunjung ini, maka pariwisata berpotensi untuk dikembangkan agar pertumbuhan jumlah pengunjung semakin meningkat untuk setiap tahunnya. Daerah tujuan wisata unggulan di Indonesia yang berpotensi meliputi Bali, Yogyakarta, Lombok, Jakarta, Bandung, Manado, Makasar, Padang dan masih banyak lagi kota atau daerah lainnya yang menjadi tujuan wisata. Salah satu daerah tujuan wisata yang menjadi andalan pariwisata indonesia adalah Sumatera Utara.

Sumatera Utara memiliki keindahan alam yang kaya dan indah seperti pegunungan, lautan, seni dan bernilai sejarah tinggi, kerajinan dan kesenian yang khas, pusat jajanan dan cendra mata serta keramahan masyarakat yang merupakan potensi pariwisata yang dimiliki Sumatera Utara. Inilah yang membuat banyak wisatawan yang ingin berkunjung ke Sumatera Utara.

Menurut tabel jumlah pengunjung wisatawan mancanegara yang berkunjung ke Sumatera Utara di atas tahun 2013 adalah tahun terbanyak wisatawan yang berkunjung ke Sumatera Utara dan terus mengalami penurunan di tahun 2014 sampai dengan tahun 2016. Melihat kondisi jumlah wisatawan yang terus mengalamai penurunan ini. Disinalah peran pemerintah di butuhkan untuk meningkatkan jumlah pengunjung yang akan melakukan wisata ke Sumatera Utara.

Provinsi Sumatera Utara memiliki 25 kabupaten dan 7 kota yang memberikan alternatif pilihan berwisata yang cukup variatif. Salah satu kabupaten yang sedang berkembang dengan kepariwisataannya adalah kabupaten Serdang Bedagai. Kawasan di Kabupaten Serdang Bedagai yang memiliki banyak daya tarik wisata yang sangat mengandakan potensi alamnya yang besar adalah Desa Pantai Cermin Kanan, Kecamatan Pantai Cermin. Keunikan yang dimiliki oleh daya tarik wisata desa pantai cermin kanan tersebut menjadi pilihan (preferensi) ketika pengunjung akan melakukan kunjungan wisata. Penetapan preferensi tersebut didasarkan oleh beberapa faktor yang mungkin akan dijadikan sebagai pertimbangan, diantaranya adalah motivasi kunjungan, kesukaan, lokasi untuk menempuh objek wisata, aksesibilitas, fasilitas dan lain sebagainya. Preferensi wisatawan merupakan pertimbangan keputusan yang dipengaruhi oleh berbagai faktor, baik itu faktor selera, motivasi, fasilitas, lokasi, aksesibilitasi, tarif harga serta jam kunjungnya.Daya tarik wisata yang berada di desa pantai cermin kanan kecamatan pantai cermin kabupaten serdang bedagai yang merupakan salah satu prefrensi 
adalah daya tarik wisata Pantai Bali Lestari. Pantai Bali Lestari ini memiliki pemandangan alam yang menarik berupa sebuah pantai yang indah serta objek-objek spesifik lainnya seperti udara yang segar dan lokasi yang menunjang sehingga Pantai Bali Lestari melengkapinya dengan sarana dan prasarana yang dapat mendukung keindahan tempat itu sendiri seperti arena bermain anak, restaurant, kolam ikan, pemancingan dan area ritel bertema Bali yang kini banyak diminati oleh para wisatawan.

Sebelumnya nama pantai ini adalah Pantai Lestari Indah yang dulunya banyak di kunjungi oleh para wisatawan yang ingin menikmati suasana pantai. Namun seiring dengan berkembangnya objek wisata yang menghadirkan banyak produk-produk yang lebih bervariatif, tidak membosankan dan dapat memberikan jasa yang lebih baik yang ada di Kabupaten Serdang Bedagai menyebabkan semakin banyak alternatif pilihan untuk berwisata, hal ini mempengaruhi preferensi pengunjung untuk mengunjungi Pantai Lestari Indah dan akan menyebabkan semakin banyak pula peluang wisatawan untuk berpindah dari satu objek wisata ke objek wisata lain. Penurunan jumlah pengunjung Pantai Lestari Indah terjadi pada tahun 2014 yaitu jumlah pengunjung untuk setiap bulannya 7000 pengunjung bahkan penurunan pengunjung paling banyak yaitu pada bulan September yaitu 5000 pengunjung (sumber: Pengelola Pantai Lestari Indah). Tantangan bagi pihak pengelola Pantai adalah mempertahankan dan memperbanyak jumlah pengunjung dengan kenaikan yang signifikan. Upaya yang di lakuakan pihak pengelola pantai untuk mengatasi tantangan ini adalah dengan melakukan revitalisasi produk. Yang di mulai dari perubahan nama pantai yang awalnya Pantai Lestari Indah kini menjadi Pantai Bali Lestari pada tahun 2015, ini dilakukan untuk mempertahankan produk dan jasa yang ditawarkan. Perubahan nama menjadi Pantai Bali Lestari ini di karenakan pengelola Pantai membuat dekorasi ataupun tema pantai yaitu seperti seakan berada di Bali. Revitalisasi produk wisata dapat menentukan keputusan pengunjung dalam memilih daya tarik wisata mana yang akan dikunjungi, suatu daerah tujun wisata akan dapat menarik minat pengunjung apabila daerah tujuan wisata tersebut dapat menyajikan produk wisata yang baik dan unik. Semakin baik dan unik produk wisata yang diberikan oleh suatu daya tarik wisata, maka akan lebih banyak pengunjung yang datang bekunjung kedaya tarik wisata tersebut yang nantinya akan meningkatkan jumlah pengunjung kedaya tarik wisata tersebut (Karim 2010:2).

\section{KAJIAN PUSTAKA \\ Preferensi Mengunjungi}

Preferensi konsumen lebih mengacu pada bagaimana perasaan seseorang atas sesuatu hal dan apa yang mereka lakukan, sehingga dapat dikatakan sebagai bentuk pernyataan dari rasa ketertarikan wisatawan atas sesuatu yang mampu menghalangi seseorang mencapai apa yang mereka kehendaki, seperti waktu, pendapatan dan jarak.

Menurut Sudibyo (2004:4) preferensi wisatawan merupakan nilai-nilai yang dianut wisatawan 
dalam menghadapi berbagai bentuk konflik alam lingkungannya. Konflik ini tidak harus konflik dalam bentuk fisik, namun pengertian konflik yang dimaksudkan meliputi konflik dalam arti perbedaan antara harapan dengan realisasi yang dirasakan dari permasalahan yang dihadapi.

\section{Revitalisasi}

Revitalisasi dapat diartikan menghidupkan kembali suatu kawasan yang sudah mati, meningkatkan kawasan yang sudah hidup,menyuntikkan sesuatu yang baru (aktivitas dan bangunan) pada suatu kawasan (Kimpraswil, 2003).

\section{Produk Wisata}

Ada beberapa pendapat yang dikemukakan oleh para ahli terhadap pengertian produk pariwisata, diantaranya : Menurut Yoeti, (2005:3) menyatakan bahwa produk wisata adalah semua bentuk pelayanan ang dinikmati wisatawan semenjak ia meninggalkan tempat tingga, selama berada didaerah tujuan wisata yang dikunjungi, hingga ia kembali pulang ketempat asalnya.

\section{Revitalisasi Produk Wisata}

Dari pengertian produk dan revitalisasi di atas dapat disimpulkan pengertian revitalisasi produk adalah menghidupkan kembali suatu kawasan wisata yang sudah mati, meningkatkan kawasan wisata yang sudah hidup, menyuntikkan sesuatu yang baru kekawasan wisata baik bagunan, fasilitas, atau pun daya tarik wisatanya. Revitalisasi produk wisata adalah salah satu strategi yang digunakan untuk meningkatkan kembali kawasan wisata agar dilirik kembali oleh konsumen.

Dalam memasarkan sebuah produk maupun jasa salah satu strategi yang sering kali dilakukan dalam prakteknya yaitu memperhatikan strategi dari atribut produk yang ditawarkan. Atribut produk wisata adalah semua bentuk pelayanan yang dinikmati wisatawan yang memiliki unsur-unsur utama yang terdiri dari Revitalisasi atraksi wisata, Revitalisasi aksebilitas (Accesibilities), dan Revitalisasi Amenital/ fasilitas (facility) (Yoeti, 2005:4)

\section{METODE PENELITIAN}

Penelitian ini dilakukan di Pantai Bali Lestari yang berlokasi di Jalan Mayjen Haji T. Rizal Nurdin Pantai Cermin kanan, Pantai Cermin Kabupaten Serdang BedagaiSumatera Utara 20987. Populasi dalam penelitian ini adalah konsumen yang berkunjung dalam satu minggu terakhir pada bulan Januari 2017 dengan jumlah 5.545 wisatawan dengan sampel sebanyak 98 wisatawan. Analisis dalam penelitian ini menggunakan analisis regresi yang bertujuan untuk mengetahui besarnya pengaruh beberapa variabel independen terhadap variabel dependen. Dalam penelitian ini analisi rgresi yang dipakai adalah analisis regresi berganda dimana secara umum data hasil pengamatan $\mathrm{Y}$ dipengaruhi oleh beberapa variabel bebas $\mathrm{X} 1, \mathrm{X} 2, \mathrm{X} 3, \ldots, \mathrm{Xn}$. Sehingga rumus umum dari regresi berganda yaitu: $\mathbf{Y}=\mathbf{a}+\mathbf{b}_{1} \mathbf{X}_{1}+\mathbf{b}_{2} \mathbf{X}_{2}+\mathbf{b}_{3} \mathbf{X}_{\mathbf{3}}+\mathbf{e}$.

Uji statistik t pada dasarnya menunjukkan seberapa jauh pengaruh satu variabel independen secara individual dalam menerangkan variabel dependan. Uji $F$ atau uji statistic $F$ pada dasarnya menunjukkan apakah semua variabel independen atau bebas yang dimasukkan kedalam model yang 
mempunyai pengaruh secara bersamasama terhadap variabel dependen atau terikat. Menurut Ghozali (2011:97), koefisien determinasi $\left(\mathrm{R}^{2}\right)$ pada intinya mengukur seberapa jauh kemampuan model dalam menerangkan variasi variabel dependen.

\section{HASIL DAN PEMBAHASAN Hasil Penelitian}

Dari hasil pengolahan SPSS diperoleh persamaan regresi tersebut adalah: $Y=7,422+\mathbf{0 , 1 5 8} X_{1}+\mathbf{0 , 2 0 6}$ $\mathrm{X}_{\mathbf{2}}+\mathbf{0 , 2 1 3} \mathrm{X}_{\mathbf{3}}+$ e. Yang berarti:

a. Konstan sebesar 7,422 dapat diartikan bahwa jika variabel $\mathrm{X}$ (Atraksi, Amenitas, Aksebilitas) tidak berubah (konstan) maka preferensi mengunjungi akan tetap sebesar 7,422.

b. Koefisien $\mathrm{X}_{1}$ sebesar 0,158 menyatakan bahwa kenaikan satu satuan Atraksi wisata akan meningkatkan preferensi mengunjungi sebesar 0,158 .

c. Koefisien $\mathrm{X}_{2}$ sebesar 0,206 menyatakan bahwa kenaikan satu satuan Amenitas akan meningkatkan Preferensi mengunjungi sebesar 0,206.

d. Koefisien $\mathrm{X}_{3}$ sebesar 0,213 menyatakan bahwa kenaikan satu satuan Aksebilitas akan meningkatkan Preferensi mengunjungi sebesar 0,213 .

Dari uraian di atas dapat disimpulkan bahwa Atraksi wisata, Amenitas, dan Aksebilitas berpengaruh terhadap Preferensi mengunjungi.

Berdasarkan olah data SPSS diperoleh hasil sebagai berikut:

1. Variabel Atraksi wisata memiliki $t_{\text {hitung }}>t_{\text {tabel }}$, yaitu sebesar 2,132 $>$ 1,986 dan taraf signifikansi sebesar $0,003<$ dari 0,05 . Hal tersebut berarti secara parsial Atraksi wisata berpengaruh positif terhadap Preferensi mengunjungi. Berdasarkan hasil tersebut maka $\mathrm{H}_{0}$ di tolak dan $\mathrm{H}_{\mathrm{a}}$ diterima.

2. Variabel Amenitas memiliki $t_{\text {hitung }}>t_{\text {tabel }}$, yaitu sebesar 2,850 $>$ 1,986 dan taraf signifikansi sebesar $0,001<$ dari 0,05 . Hal tersebut berarti secara parsial Amenitas berpengaruh positif terhadap Preferensi mengunjungi. Berdasarkan hasil tersebut maka $\mathrm{H}_{0}$ di tolak dan $\mathrm{H}_{\mathrm{a}}$ diterima.

3. Variabel Aksebilitas memiliki $t_{\text {hitung }}>t_{\text {tabel }}$, yaitu sebesar 2,601 $>$ 1,986 dan taraf signifikansi sebesar $0,000<$ dari 0,05 . Hal tersebut berarti secara parsial Aksebilitas berpengaruh positif terhadap Preferensi mengunjungi. Berdasarkan hasil tersebut maka $\mathrm{H}_{0}$ di tolak dan $\mathrm{H}_{\mathrm{a}}$ diterima.

Diperoleh nilai $F_{\text {hitung }}$ sebesar 3,737 lebih besar dari $F_{\text {tabel }}$ sebesar 2,70 dan taraf signifikansi sebesar $0,000<0,05$. Karena $F_{\text {hitung }}>F_{\text {tabel }}$ yang berarti bahwa $\mathrm{H}_{0}$ ditolak dan $\mathrm{H}_{\mathrm{a}}$ diterima, sehingga dapat disimpukan bahwa hipotesis yang menyatakan Atraksi wisata, Amenitas, dan Aksebilitas secara simultan di duga berpengaruh positif terhadap Preferensi mengunjungi Pantai Bali Lestari, dinyatakan diterima.

Diperoleh

koefisien determinasi R Square $\left(\mathrm{R}^{2}\right)$ sebesar 0,613. Nilai Adjusted $R$ square menunjukkan bahwa variabel Indepeden yaitu Atraksi wisata $\left(\mathrm{X}_{1}\right)$, Amenitas $\left(\mathrm{X}_{2}\right)$, Aksebilitas $\left(\mathrm{X}_{3}\right)$ mampu menjelaskan variabel dependen yaitu Preferensi mengunjungi $(\mathrm{Y})$ sebesar 0,613 atau 
$61,3 \%$, sedangkan $\quad 38,7 \%$ sisanya dipengaruhi oleh faktor-faktor lainnya yang berasal dari luar variabel yang diteliti.

\section{Pembahasan}

Setiap perusahaan mempunyai strategi pemasaran tersendiri. Strategi pemasaran ini dilakukan agar perusahaan mampu bertahan dalam persaingan. Salah satu strategi pemasaran yang dilakukan Pantai Bali Lestari adalah merevitalisasi produk wisata yang di mulai dari Atraksi Wisata, Amenitas, Aksebilitas. Mengingat bahwa Pantai Bali Lestarii merupakan usaha yang bergerak dalam bidang pariwisata tentu Atraksi wisata, Amenitas, Aksebilitas akan menjadi salah satu tolak ukur bagi para wisatawan.

Preferensi mengunjungi adalah sebuah proses dimana wisatawan mengenal masalahnya, mencari informasi mengenai tempat wisata dan mengevaluasi seberapa menarik tempat wisata tersebut dapat memecahkan masalahnya, yang kemudian mengarah kepada keputusan untuk memilih mengunjungi (preferensi mengunjungi) tempat tersebut.

Atraksi wisata berpengaruh positif dan signifikan terhadap preferensi mengunjungi Pantai Bali Lestari terbukti. Adanya pengaruh positif ini dikarenakan Atraksi wisata dengan konsep pantai memberikan nuansa baru bagi wisatawan yang tidak hanya berorientasi dengan keindahan pantai, namun saat ini Atraksi wisata juga menjadi pertimbangan bagi para wisatawan. Hal ini juga sesuai dengan penelitian terdahulu oleh Stevianus (2014) yang mengatakan bahwa Atraksi wisata mempunyai pengaruh terhadap Preferensi mengunjungi.

Amenitas berpengaruh positif dan signifikan terhadap preferensi mengunjungi Pantai Bali Lestari terbukti. Pengaruh positif dan signifikan ini disebabkan karena Amenitas yang disediakan dengan kebutuhan yang diharapkan wisatawan terpenuhi. Hal ini juga sejalan dengan (Muljadi, 2010: 89) amenitas adalah berbagai fasilitas yang dapat memberikan kenyamanan dan kepuasan bagi para wisatawan selama mereka melakukan perjalana wisata disuatu daerah tujuan wisata. Hal ini juga sesuai dengan penelitian terdahulu oleh Sulistiono (2010) yang mengatakan bahwa Amenitas mempunyai pengaruh positif terhadap Preferensi mengunjungi.

Aksebilitas berpengaruh positif dan signifikan terhadap Preferensi mengunjungi terbukti. Hal ini disebabkan wisatawan merasa puas dengan prasarana yang disediakan menuju Pantai Bali Lestari. Selain itu, harga tiket masuk juga sesuai dengan keindahan, konsep yang diberikan Pantai Bali Lestari Aksebilitas adalah mudah atau sulitnya wisatawan menjangkau destinasi yang diinginkan ( Pitana dan Diarta,2009: 130). Hal ini juga sesuai dengan penelitian terdahulu oleh Sitorus (2008) yang mengatakan bahwa Aksebilitas mempunyai pengaruh positif terhadap Preferensi mengunjungi.

\section{SIMPULAN}

Atraksi Wisata memiliki pengaruh positif terhadap Preferensi mengunjungi Pantai Bali Lestari. Amenitas memiliki pengaruh positif 
JURNAL PLANS

Penelitian Ilmu Manajemen \& Bisnis

ISSN: $1978-7057$

E-ISSN: 2527-306X

terhadap Preferensi mengunjungi Pantai Bali Lestari. Aksebilitas memiliki pengaruh positif terhadap Preferensi mengunjungi Pantai Bali Lestari. Atraksi wisata, Amenitas, Aksebilitas berpengaruh secara bersama-sama (simultan) terhadap Preferensi mengunjungi Pantai Bali Lestari.

DAFTAR PUSTAKA

Ghozali, Imam. 2011. Alikasi Analisis Multivariante Dengan Program SPSS 20. Semarang: Badan Penerbit Universitas Diponegoro

Karim, Sayid Abdul. 2010. Revitalisasi Dan Inovasi. Bandung : Angkasa

Kimpraswil. 2003. Revitalisasi Produk Wisata. Bandung : Angkas.

Muljadi A.J. 2009. Kepariwisataan Dan Perjalanan Jilid 1. Jakarta: PT. Raja Grafindo Persada.

Pitana, I G Dan Diarta, K.S (2009). Pengantar Imu Pariwisata Yogyakarta: C.V Andi
Sitorus, Monang. 2008. Pengaruh Atraksi , Fasilitas Dan Aksebilitas Terhadap Nilai Pelanggan Dan Citra Objek Wisata Danau Toba Di Kabupaten Toba Samosir Provinsi Sumatera Utara. Januari 2017. Vol. 2. No.1

Sudibyo. 2004. Wisata Konvensi. Jakarta: Gramedia Pustaka Utama

Sulistiono, Ari Budi. 2010. Pengaruh Kualitas Pelayanan, Fasilitas Dan Lokasi Terhadap Keputusan Menginap. Januari 2016. Vol. 2 No. 1

Stevanus.2014. Pengaruh Atraksi Wisata, Fasilitas, Kualitas Pelayanan Terhadapa Kepuasan Pengunjung Di Taman Marga Satwa Ragunan. Jakarta, Februari 2017. Vol.9 No.2

Yoeti, Oka. 2005. Pemasaran Pariwisata Terpadu. Bandung : Angkasa 